\title{
Music and the Production of Place: INTRODUCTION
}

\section{Transforming Cultures eJournal, \\ Vol. 4 No 1 April 2009 \\ http://epress.lib.uts.edu.au/journals/TfC}

\section{Tony Mitchell ${ }^{1}$}

Regardless of the words, it seems the melodic contour of the song described the nature of the land over which the song passes.

...'So a musical phrase', I said, 'is a map reference?'

'Music', said Arkady, 'is a memory bank for finding one's way about the world'.

Bruce Chatwin, The Songlines, London, Picador, 1988, pp.119-120.

The articles in this issue examine various ways in which music and musicians produce place, either in terms of the 'psychogeographies' of living spaces, cityscapes and landscapes (as defined by Guy Debord in 1955 as 'the study of the precise laws and specific effects of the geographical environment, consciously organized or not, on the emotions and behaviour of individuals'), or through the transnational evocation of lost homelands, spaces of migration, or syncretic expressions of place. In the process, they explore what Sara Cohen has referred to as:

music's effectiveness in stimulating a sense of identity, in preserving and transmitting cultural memory, and in establishing the sensuous production of place. Individuals can use music as a cultural 'map of meaning', drawing upon it to locate themselves in different imaginary geographies ... and to articulate both individual and collective identities (Cohen 1998:286-287).

The articles published here have been developed from papers given at a symposium held at UTS in May 2008, and cover a wide range of different musical forms of production from 'art music' to 'world music', as well as rock, dance music, jazz and hip hop and the places both where they are produced and that they produce. Some also examine ways in which music migrates from one place to another; as George Lipsitz has stated:

\footnotetext{
${ }^{1}$ Tony Mitchell is a Senior Lecturer in Writing and Cultural Studies, University of Technology, Sydney.
} 
precisely because music travels, it also augments our appreciation of place. ... Through music we learn about place and about displacement. Laments for lost places and narratives of exile often inform, inspire and incite the production of popular music ...Intentionally and unintentionally, musicians use lyrics, musical forms and specific styles of performance that evoke attachment to or alienation from particular places. (Lipsitz, 1994:3-4).

The relation of music to place is often expressed in terms of soundscapes, a concept referring to acoustic environments first used by Canadian composer and musicologist R. Murray Schafer in his 1969 book The New Soundscape, and much used (and over-used) since. A wide variety of different kinds of soundscape are covered here. The geographical route of the papers begins in Sydney and moves outward. First Theo van Leeuwen situates music in various geographical contexts, drawing on examples from classical music, dance music and soundscapes. Then crime writer, slide and lap steel guitarist and music writer Peter Doyle explores the 'sonic sublime' contained in two well-known popular songs located in the Maroubra area of Sydney where he grew up the Atlantics' celebrated instrumental 'Bombora', and Aboriginal singer Mac Silver's recording of Dave Duncan's song about Long Bay gaol, 'Malabar Mansion'. Both songs, he notes, are about 'imaginary elsewheres', and are 'figures on ground', to use Schafer's terms for musical perspective, that become fluid but potent measures of the places in which they were created, and which they recreate.

Football songs have long been regarded as a way of measuring territory, especially on the terraces of British soccer matches. What happens when these songs are transplanted to Australia, and to the relatively new homegrown soccer A league? Ian Collinson has hung out with the Cove, the supporters' group attached to the Sydney FC team, and through an examination of their website, studies their 'plainsong', which mainly consists of well-known songs given reinvented lyrics which express both a local and a global identity for the fans of the 'world game' through acts of secular ritual producing what Christopher Small has called 'musicking' (1998:95). Despite the often hilariously obscene, and seemingly homophobic and misogynist lyrics of these songs, Collinson argues that they are fundamentally about community building, 'joining local and distant spaces through song'.

The lyrics of the repertoire of Sydney-based rock band the Whitlams has contained numerous references to the inner west suburb of Newtown, to the extent that they have 
been satirised for their seemingly constant reminders of their place of origin. Drawing on earlier work on the group's relation to Newtown by music geographer John Connell, Sydney street press Drum Media journalist Liz Giuffre argues that the more separated the group have become from their Newtown 'roots' through their increasing national and international success, the more they have referenced Newtown as an indicator of authenticity. The Sydney dance music scene, as Ed Montano argues, has often been marginalised on the global stage, and derided as derivative of US and UK trends, and excessively reliant on overseas DJs. Drawing on extensive interviews with Sydney DJs and practitioners in the local scene, Montano argues that due to increasing use of the internet to obtain music, local DJs are now able to keep abreast of global trends far more easily, and while local promoters and DJs still tend to rely heavily on what is largely an import culture, due to the lack of local dance music producers, Sydney nonetheless has its own distinctively local identity as a dance music locale.

Moving up to Northern New South Wales, cultural geographer Chris Gibson examines music scenes on the far north coast, especially in centres of alternative culture like Byron Bay and Nimbin, tracing two different narratives of their history and development of a regional identity, both cultural and economic, from an extensive archive of hundreds of recordings, flyers, posters and newspaper clippings. The diversity of music forms and genres, as well as the mixture of local, regional, national and global musical influences, defines the area as an 'alternative' site of performances of numerous music practices that are geographically fluid and give the region a complex musical identity.

In Canberra, Charles Fairchild offers a close-up examination of the performative practices of a DJ at a local community music station, arguing that they constitute 'a series of communicative acts that are personal and institutional simultaneously'. Using Bakhtin's notions of the dialogic and 'heteroglossia', Fairchild suggests that the radio DJ partakes in a 'civil aesthetic discourse' which links the locality of his CD box in his home and the studio into a broader and multiple field of listening. Moving down to Melbourne, Linda Kouvaras analyses two examples of Australian sound art which both, not entirely coincidentally, utilise toilets as part of their musical soundcapes. Both The Gordon Assumption by Sonya Leber and David Chesworth (2004), which was performed at an abandoned subterranean toilet block, and "Tears", the final movement 
of Andrée Greenwell's Passion (1993), which employs the sound of a flushing toilet, also use glissandi, women's voices and water in metaphorical transgressions of place which are also feminist statements. Kouvaras places these works in the historical context of the use of water and women in preceding modernist sound works.

Aboriginal hip hop, as Cameron White demonstrates, is not something which has simply sprung from nowhere, but is part of an ongoing conversation interacting not just with the origins of African-American hip hop in the South Bronx, but also with traditional aspects of Aboriginal culture such as storytelling, dance and cave painting. As Wire MC, who gave an address at the symposium which is extracted on a sound file following White's paper, has stated, 'hip hop has always been part of Aboriginal culture'. This indicates that it is the latter, not the former, which is the host culture in terms of Australian Aboriginal appropriations of hip hop, which also engage which Aboriginal forms of reggae which developed after Bob Marley's tour of Australia in 1979. In both cases, syncretic forms of music are indigenised by Aboriginal musicians, and also become vehicles for political statements of Aboriginal militancy which take on transnational forms.

Tasmania has long been marginalised as a locality for music production in Australia, despite being the location of the first-ever sound recordings (on wax cylinders) in Australia of songs by Aboriginal singer Fanny Cochrane Smith in 1899 and 2003, which was also the only sound recording made of the Tasmanian Aboriginal language.

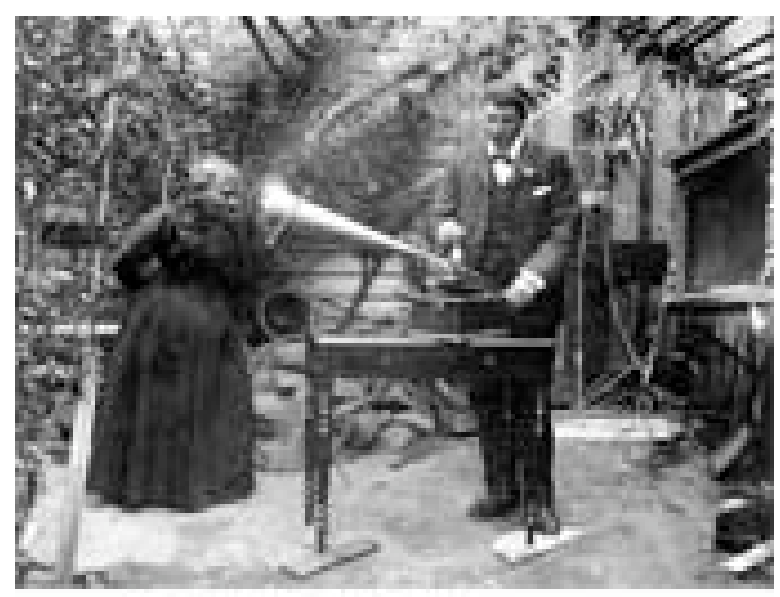

Fanny Cochrane Smith recording with Dr Harold Watson. Photo courtesy of the Museum of Tasmania.

Its island isolation from the rest of Australia means Tasmania is often overlooked as a site of music production, and local musicians often have to rely on the more 
infrastructure-rich Melbourne as a site of production and distribution for their music. At the same time there is a long tradition of 'Tasmanian gothic' and 'Tasmanian grotesque' linking the island's convict past and sites of Aboriginal massacres with its rugged, sometimes treacherous landscape and its weird folk art, which has frequently found expression in literature and visual arts, and occasionally in music. Julien Poulson is a musician who recently returned to Tasmania after a long absence, and set about creating music which expressed the gothic features of the island, not in terms of any trendoid Nick Cave-like 'goth' sensibility, but connecting the music directly to the historical features of the countryside. In their analysis of his group the Green Mist's 2007 album Next Stop Antarctica, Keryn Stewart and Helen Hopcroft locate it within a 'Tasmanian imaginary', which has a real basis in the 'place memory' of the history of Recherche Bay written by Poulson's father. Drawing on Maria Tumarkin's notion of 'traumascapes', the authors trace the sense of Tasmanian gothic in the Green Mist's music, as well as relating it to the more recent notion of 'hauntology' in the music of labels such as the UK-based Ghost Box which found sounds and sampled historic sounds are used to evoke imagined 'lost' worlds. They also trace the Green Mist's and Poulsen's affective, virtual and musical links to other 'extreme' places such as Darwin and Phnom Penh, and question whether notions of 'the end of the world' has any real meaning in an age in which the globe is shrinking.

Moving beyond the borders of Australia, Jennifer Cattermole examines the expressions of place and locality contained in indigenous Fijian sigidrigi (sing-drink) songs through the construction of both real and imagined communities in band names, song lyrics and aspects of musical style. By naming kinship groups and home places, these songs give meaning and value to particular places, as well as linking with the traditional Fijian meke dance to "index roots and routes" in a manner perhaps similar to the "lift-up-oversounding' of the music of the Bosavi people in Papua New-Guinea studied extensively by US ethnomusicologist Steven Feld, who work has set a benchmark for the analysis of the relationships between music and place (Feld: 2001). Drawing on Feld's work, Tony Mitchell takes us to the other extremity of the world on an Icelandic and Scandinavian musical psychogeographic tour, from the 'Nordic tone' of Norwegian and Finnish jazz musicians who have arguably displaced the USA in creating a current 'centre' for contemporary jazz recording and performance, to the Icelandic imaginary of ambient rock group Sigur Rós, who have rivalled Björk as an internationally successful 
exponent of Icelandic rock music. From the 'Southern Gothic' of Tasmania and its proximity to Antarctica, we arrive at the Ultima Thule of Iceland through an examination of the poetics of place in music.

Two further papers contest the centrality of place in music, invoking Gilles Deleuze's concept of the 'any-space-whatever'. John Scannell favours the notions of 'non-place' and 'not-belonging' as well as 'derelict spaces' as sites for the production of music, especially African-American forms of music such as the funk of James Brown and the techno music which emanated from the post-industrial urban wasteland of Detroit. Ghettos such as the South Bronx can be seen as 'non-places', and Scannell uses the work of Paul Gilroy on the 'black Atlantic' and 'double consciousness' to emphasise the music of the African diaspora's reliance on mobile, fluid 'routes' of migration rather than 'roots' based in emplacement. Collin Chua provides a history of music video as a further example of a musical form developing in the 'any-space-whatever', where the virtual space of mediation is foremost, and Appadurai's 'mediascapes' are the primary field of communication. Places both real and imagined are circulated globally in music videos, which offer a form of 'creative consumption' in which spectators are linked in a virtual community.

Finally, Mariana Rodriguez examines the lyrics and music of the highly popular Mexican corrido group Los Tigres Del Norte, both as grass roots representatives of the Chicano and Mexican-American migrant community, and as exponents of narcocorridos, a highly controversial genre of music which has recently led to several mob-style murders of musicians in Mexico and which often celebrates drug dealers who travel across the US border and flaunt their outlaw status in the face of US imperialism. The enormous popularity of the group throughout the Spanish-speaking world has seen their anti-racist, anti-imperialist and anti-macho message dispersed throughout a huge dispora.

Whether emanating from and evoking places or non-places, music is always situated in the place and the moment of its performance, reception, recording and interpretation; and whether consciously or not, it arguably produces or reproduces the circumstances and location of its production and consumption. Listening to Sigur Rós's symphonic rock on a summer night in Sydney is a vastly different experience from listening to 
Wire MC's hip hop in Europe or Latin America; but in both cases it is arguably impossible not to regard the musicians and the music as representing both who they are and where they are from. As Feld noted of the Bosavi, "the journey is completely in the listener's head ... Knowing where you are is knowing who you are" (2001: 205).

\section{Acknowledgments}

Thanks to Lindi Todd of Transforming Cultures, UTS for her organisational and editorial work, to Emily Bullock for the cover photo (taken in Dunedin, New Zealand, in 2008), and to the numerous anonymous referees throughout Australia as well as in the UK and Europe who helped to shape these articles into their final form.

\section{Bibliography}

Cohen, S. (1998) 'Sounding out the City: Music and the Sensuous Production of Place' in Leyshon, D. Matless and G. Revill (eds.) The Place of Music, London: Guildford Press, 1998:286-287.

Debord, G. (1955) Introduction to a Critique of Urban Geography, Les Lèvres Nues 6 http://library.nothingness.org/articles/SI/en/display/2

Feld, S. (2001) "Lift-Up-Over Sounding” in David Rothenberg \& Marta Ulvaeus, (eds.) The Book of Music and Nature, Middletown: Wesleyan University Press,193206.

Lipsitz, G. (1994) Dangerous Crossroads, London, Verso.

Schafer, R. M. (1969) The new soundscape: a handbook for the modern music teacher, Ontario : BMI Canada.

Small, C. (1998) Musicking: the Meaning of Performing \& Listening, Middleton, CT: Wesleyan University Press. 